\title{
"Putting a Foot in the Door": Volunteer Hiring and Organizational Form
}

\author{
Michael Vlassopoulos* \\ University of Southampton
}

June 2015

\begin{abstract}
Mission-oriented organizations, such as nonprofit organizations and NGOs, rely critically on volunteer recruitment to achieve their organizational goals. Besides serving as an outlet of altruistic motives, volunteering often acts as a stepping-stone for a paid position in the nonprofit sector. This paper provides an explanation for the fact that nonprofit employers are uniquely able to attract such volunteers with social concerns and career aspirations and for the related observation that nonprofits figure prominently in mission-related activities. The theory is predicated on that - by committing to not distributing profits - nonprofit incorporation relaxes the incentive constraint that employers face when implicitly contracting with volunteers. The not-for-profit commitment is shown to be effective only in activities where producers, who can choose to be for-profit or nonprofit, care about the level of the service being provided.
\end{abstract}

JEL Classification: D21, H41, J41, L31

Keywords: volunteers, nonprofit organizations, incentive schemes, relational contracts, deferred compensation, intrinsic motivation

${ }^{*}$ Economics Department, Social Sciences, University of Southampton, Southampton SO17 1BJ, UK. E-mail: M.Vlassopoulos@soton.ac.uk 


\section{Introduction}

Volunteering constitutes a considerably large and increasing share of the nonprofit sector's contribution to economic activity, in most advanced economies. ${ }^{1}$ Besides volunteering for altruistic reasons - a desire to help others or contribute to an important cause - there is widespread belief that volunteering can be a source of professional development by providing work experience and a chance to develop skills that strengthen employability. ${ }^{2}$ This is especially true for those pursuing employment in the nonprofit sector where volunteering experience appears to be a prerequisite for any type of career. This paper takes the altruistic motivations and the career concerns of volunteers as a point of departure and provides an explanation for the following salient patterns (1) nonprofit organizations attract the overwhelming share of volunteers ${ }^{3}$ that meet this profile and (2) volunteer-hiring nonprofits are concentrated in sectors, where the goods and services produced can be conceived as having a collective good component and which generate nonpecuniary benefits to those involved in their delivery. Education, healthcare, childcare, international aid, the arts, religious and philanthropic foundations, and the vast social services are examples of such fields. These contrast with most other activities, regularly provided by profit taking firms, where intrinsic motivation is less of a consideration.

The challenge that this paper poses is to explain the above set of observations as an equilibrium outcome without positing that workers motivated by concerns for social outcomes have an exogenous disposition for working at nonprofit establishments or assuming that nonprofit and for-profit producers have respective ex ante advantages in the delivery of goods and services of different character. To this end, I develop a model with two sectors (a mission sector and a non-mission sector),

\footnotetext{
${ }^{1}$ For example, in the US the value of volunteer work evaluated at average private wages stood at $\$ 283.84$ billion in 2010 (The Nonprofit Almanac 2012). Further evidence of the importance of volunteers for the nonprofit sector is reported in Salamon et al. (2007), who estimate that volunteers' effort accounts, on average, for more than a quarter of the sector's contribution to GDP.

${ }^{2}$ This is supported by research that studies factors that determine the decision to supply volunteer time, suggesting that besides purely altruistic motives people may engage in volunteering activities to improve their employment opportunities: Menchik and Weisbrod (1987), Day and Devlin (1998), Segal and Weisbrod (2002), Gunderson and Gomez (2003), Handy et al. (2010), Sauer (2012). For instance, Sauer (2012) estimates that the economic returns to volunteering are relatively more important than non-economic returns for women in the US, while Day and Devlin (1998) report evidence of a 6-7 percent return of volunteering in annual earnings for Canadian workers. Surveys also support these findings. For example, the National Survey of Giving, Volunteering, and Participating (2007), which provides a snapshot of the state of voluntary and civic action in Canada, reveals that almost a quarter (23\%) of volunteers agreed that improving job opportunities was a reason for volunteering, while around half of volunteers reported that they volunteered to explore their own strengths. See Hall et al. (2009), chart 2.13, pg 35. Moreover, another survey from the UK suggests that employability is a more frequent motivation for younger individuals (Low et al., 2007).

${ }^{3}$ In 1998, the distribution of full-time volunteers by sector in the U.S. was 68.5 percent nonprofit, 26 percent government and 5.5 percent for-profit sector. See the New Nonprofit Almanac and Desk Reference, Figure 1.7, pg 48.
} 
where heterogeneous (some mission motivated and some not) managers (principals) and workers (agents) are matched, choosing organizational form (for-profit, nonprofit), employment contract and sector. Note that in order to address the previously mentioned challenge the analysis starts from a position of ex-ante symmetry: (a) the intrinsic benefit that caring managers and workers derive in the mission sector is attached to the job that they do, not the identity of the organization (nonprofit or for-profit) in which they do it; ${ }^{4}$ (b) workers are equally productive working for either type of employer; and (c) managers have access to a common production technology regardless of the organizational form they select. Therefore, besides the restriction in the appropriation of profits there are no ex ante structural differences between for-profit and nonprofit status. I then proceed to demonstrate how the observed configuration (nonprofit firms hiring volunteers in the mission sector) arises endogenously in the equilibrium of the model, among the host of ex ante possible (firm-type/employment structure/sector) combinations.

An important feature of the analysis is that workers' effort and output are unverifiable by third parties and as a result performance-contingent remuneration is infeasible $;^{5}$ this element is present in both sectors and for all types of firm. One standard solution to this incentive problem is the use of implicit contracts that are self-enforcing and that take advantage of the long-term aspect of the employment relationship: a worker receives a fixed payment that exceeds opportunity costs as long as performance has been satisfactory and is dismissed otherwise. This type of compensation, namely a wage set above the market clearing rate (efficiency wage), is known to induce important labor market inefficiencies - sub-optimal employment levels. Here, motivated by the observation that some workers (interns and volunteers) are induced to undertake unpaid or very low pay work by the possibility of rewards in the form of future employment by the same or some other employer, I argue that this two-tier employment structure provides a more efficient solution to the problem of incomplete employment contracts: it allows firms to extract some of the rents that workers have to be offered later on as paid workers in order to supply effort, thus dampening the distorting effect arising from providing incentives with payments above opportunity cost. ${ }^{6}$

I consider two alternative incentive structures, which in the interest of facilitating exposition I refer to as:

\footnotetext{
${ }^{4}$ This is not to deny that individuals might receive direct benefits from founding or working for a nonprofit firm. Here we wish to explore whether we can explain the observed patterns of nonprofit activity without assuming such direct rewards.

${ }^{5}$ The notion that workers' performance cannot be verified in court is borrowed from the incomplete contracts literature and has been widely applied to agency models of employment, see Malcomson (1999).

${ }^{6}$ The possibility that employers use deferred payments as a means of providing incentives has been studied, in a different context, by Lazear (1981) and by Akerlof and Katz (1989).
} 
- Volunteering: A worker is hired as an unpaid volunteer and is subsequently transferred to a paid position not necessarily at the firm where he has volunteered (incentives are sector-wide).

- Internship: A worker is hired as an unpaid intern and is subsequently promoted within the firm he has interned, when a vacancy is created (incentives are firm-specific).

The key difference between volunteering and internship is that time spent volunteering elsewhere is treated "as if" it were volunteered at the firm - much like actual volunteering occurs in reality whereas interns are promoted at the firm where they intern. In both structures a worker is willing to work for a period with no pay if he anticipates that he will be subsequently promoted to a wage position, yielding an expected lifetime utility no less than his outside option. But notice that the hiring of volunteers (or interns) introduces a commitment problem on the side of the employer, as firms have incentive to recruit unpaid workers, promising them promotion to paid positions, and then renege on the promise. It is well known from the theory of repeated games that repeated interaction can help overcome these problems. The dynamic interaction between multiple firms and workers is formally studied as a repeated game and a characterization of the equilibrium strategies supporting 'volunteering' and the 'internship' structure is provided.

An additional component of the present setting is that managers and workers can be intrinsically motivated and derive nonpecuniary benefits from contributing to the production of mission goods (e.g. nurses, teachers, aid workers). Motivated agents are typically heterogeneous in terms of mission preferences - what activity to pursue and how to pursue it - and usually some hands-on experience is required before an individual can learn enough about the different causes to be able to identify a preferred mission. For example, the manager of an international aid agency or an aid worker may prefer working for an organization with a particular religious outlook, or they may develop through experience a preference over the targeted group of beneficiaries (which group is more needy). Because the main parties involved may have different views about how the project should be carried out, preference alignment is an important determinant of the quantity of the mission good. ${ }^{7}$

Volunteering facilitates the matching of like-minded organizations and workers, which improves the impact of the mission activity as well-matched pairs are more productive: a volunteer works

\footnotetext{
${ }^{7}$ The role of matching in principal-agent pairs with heterogeneous preferences is explored in Besley and Ghatak (2005), who show that better matching leads to higher effort and productivity. Here we take as given the proposition that better matched pairs are more productive in order to focus on how the interaction between the choice of organizational form (for profit or nonprofit) and incentive structure (volunteering or internship) can lead to more efficient matching.
} 
for a period of 'exploration', then as his mission preferences become known he can transfer to a matching firm, when a vacancy is created. ${ }^{8}$ By contrast, internships match workers and organizations randomly, as when an intern joins the firm his mission preferences have not been determined. Therefore, from employers' perspective volunteer hiring is the preferred hiring practice in the mission sector because it can generate more efficient matching.

Nothing in the structure of the model sketched so far suggests that a rational manager would choose nonprofit over for-profit status, since the only effect of this choice is that the manager's pecuniary payoff from operating the firm is reduced. A possible reason would be that nonprofits are at an advantage in terms of being able to sustain volunteer hiring. But does the nonprofit incorporation relax the incentive compatibility constraint that makes commitment to hiring volunteers credible? The key insight of this paper is that the answer to this hinges on the type of activity (mission-oriented or not) that is undertaken. In particular, if volunteering only raises profits (true by construction in the non-mission sector) then a nonprofit firm does not have a particular advantage over for-profit firms. This is because while for a nonprofit manager the benefit from cheating is weaker - under nonprofit status profits are less valuable for managers because they can only be enjoyed as perks - so is the reward for honest behavior. Therefore, in this case a nonprofit manager's promise of honest behavior is not more credible than the one of a for-profit manager. On the other hand, if volunteering also enhances the quantity of the service provided - because of better matching - and managers care about quantity, then nonprofit status is helpful in solving employers' moral hazard problem (true in the mission sector). The intuition is that a nonprofit manager will discount more heavily the fact that if she cheats on volunteers quantity will suffer and hence a smaller profit (reputational rent) is needed to maintain incentive compatibility.

Thus, the model accounts for the observed patterns of entry by sector: nonprofits engage in the provision of goods and services where better matching on mission preferences improves quantity, while in sectors where missions play no role, nonprofit incorporation is not essential and for-profit status will be preferred. In addition, the analysis explains why otherwise similar nonprofit and for-profit organizations will select different incentive structures to motivate their workers. In equilibrium, nonprofit organizations select the volunteering organizational structure while for-profit organizations utilize the internship. These features are in tune with the patterns of employment structure, work force characteristics and firm-type entry across sectors that we observe in many modern economies.

\footnotetext{
${ }^{8}$ Johnson (1978) and Jovanovic (1979) develop models of job shopping and matching.
} 
The rest of the paper is organized as follows. The next section discusses the related literature in greater detail. Section 3 introduces the environment of the model; section 4 characterizes the two types of relational employment contract, while section 5 analyzes the choice of organizational form and employment relational contract in each sector. Section 6 concludes.

\section{Related Literature}

This paper is related to the literature that has identified circumstances where nonprofit status may be a valuable commitment against opportunistic behavior that arises because of various forms of contractual incompleteness. For instance, Glaeser and Shleifer (2001) argue that nonprofit incorporation is a valuable mechanism for an entrepreneur because, by weakening incentives to maximize profits, it credibly commits to customers that non-contractible quality will be higher, while in Rowat and Seabright (2006), nonprofit status is a valuable signal for aid agencies because it reassures donors that their funds will be indeed directed to unverifiable development projects and not be skimmed off. Francois (2000, 2003) establishes conditions under which a nonprofit manager, by relinquishing residual claims to profits, faces weaker incentives to adjust production after a worker has shirked. When workers care about the level of the public good produced this commitment is shown to be valuable in that it reduces the wage that has to be offered to induce workers' non-contractible effort. Ghatak and Mueller (2011) incorporate the above interaction between the manager and the worker into a labor market setting in order to study how labor market conditions affect organizational choice. None of these papers consider the issue of whether the nonprofit commitment helps sustain volunteer hiring and sorting which is the main focus here.

Several recent papers study the provision of incentives and the screening of intrinsically motivated workers, among others Handy and Katz (1998), Murdock (2002), Glazer (2004), Francois (2007), Delfgaauw and Dur (2007, 2008), Prendergast (2007). ${ }^{9}$ This paper builds on the contribution by Besley and Ghatak (2005), who study incentive design issues in an environment with mission-motivated principals and agents. Their emphasis is on the role of matching of principals and agents on mission preferences and the effects of competition on productivity and the power of incentives, but they abstract from issues concerning organizational form which are central here. Specifically, the contribution of the present paper is that it presents a plausible avenue (volunteer hiring and sorting) which interacting with the endogenously chosen organizational status allows

\footnotetext{
${ }^{9}$ See Francois and Vlassopoulos (2008) for a survey of this literature.
} 
mission-driven entrepreneurs to match with like-minded workers and therefore play the efficiency enhancing role emphasized by Besley and Ghatak (2005).

The analysis of the relational contract between managers and workers follows the literature on efficiency wages (Shapiro and Stiglitz, 1984), and the more recent formalization of such arrangements as self-enforcing implicit contracts. Specifically, MacLeod and Malcomson (1989) (under symmetric information) and Levin (2003) (under adverse selection and moral hazard) have shown, in a repeated game framework, the existence of an equilibrium outcome where firms can use implicit self-enforcing contracts to motivate workers, provided there is sufficient rent for both parties from the continuation of employment. ${ }^{10}$ Optimal self-enforcing contracts can take the form of efficiency wages or performance bonuses depending on market conditions. In particular, MacLeod and Malcomson (1998) have shown that efficiency wages are likely to arise in markets where there is excess supply of workers, while performance-related bonus payments in markets with excess demand for workers.

\section{The Model}

\subsection{Primitives}

I consider an economy with discrete time and infinite time horizon consisting of two sectors: a mission-oriented and a non-mission-oriented sector, denoted by $m$ and $n$ respectively. Two groups of agents exist in the economy: managers and workers. ${ }^{11}$ There is heterogeneity in mission preferences in both groups. Specifically, I consider three types of workers, indexed by $i$, and managers, indexed by $j$, with $i, j \in\left\{u, m_{1}, m_{2}\right\}$. Type $u$ managers and workers are motivated exclusively by monetary rewards. I refer to type $u$ agents as unmotivated. Types $m_{1}$ and $m_{2}$ are referred to as missionmotivated in light of the fact that, besides the usual pecuniary motivations, they are driven by a concern about the missions pursued by the organizations they join. I allow for a distinction between $m_{1}$ and $m_{2}$ which has one of two possible interpretations. It can either reflect the differences in focus among the variety of subfields of public good activity (e.g. advocacy/activist versus direct care provider), or it can reflect differences in some attribute (e.g. religious affiliation versus secular) within some specific subfield (e.g. education) of the mission sector.

\footnotetext{
${ }^{10}$ Dur and Tichem (2013) studies how altruism between managers and employees affects relational incentive contracts.

${ }^{11}$ For clarity, we shall refer to managers using feminine pronouns and to workers using masculine.
} 


\subsection{Production}

There are three goods in the model: two produced goods $g_{m}$ and $g_{n}$, corresponding to the mission and the non-mission sector respectively, and a non-produced numeraire good $y$. Production of $g_{m}$ and $g_{n}$ is undertaken by organizations - established as either for-profit or nonprofit - which consist of a manager employing two workers. Details about the differences between the two types of institutions are provided further on. Workers do not care directly about the type of organization they work for and are equally productive working for either type of provider. All organizations in each sector, have access to a common sector-specific production technology, $g_{s}\left(e_{1}, e_{2}\right)$, where $s \in\{m, n\}$ and $e_{i} \in\left\{e^{l}, e^{h}\right\}$, which describes how the combined effort choices of the two workers and the entrepreneurial input of the manager translate into the production of the organization's service, $g_{m}$ or $g_{n}$. I assume that each worker can choose between two effort levels: high effort $\left(e=e^{h}\right)$ with corresponding output $g_{s}\left(e_{1}^{h}, e_{2}^{h}\right)=g_{s}^{h}$, and low effort $\left(e=e^{l}=0\right)$ which yields a normalized output $g_{s}\left(e_{1}^{l}, e_{2}^{l}\right)=0$. When only one of the workers shirks production level falls but not all the way to zero: $g_{s}\left(e_{1}^{h}, e_{2}^{l}\right)=g_{s}\left(e_{1}^{l}, e_{2}^{h}\right)=\zeta$, where $0<\zeta<g_{s}^{h}$.

In the mission sector, if, in addition to high effort, workers' type matches the type of the organization I assume that preference congruence has a beneficial impact on productivity and hence provision of $g_{m}$ is increased to $\widehat{g}_{m}>g_{m}^{h} .{ }^{12}$ To be concrete, imagine that there are two sets of actions that workers can take: one set is costly to them to provide, and shirking on this dimension will eventually be detected by the manager of the organization. These actions, denoted by $(e)$ in the model, are responsible for the organization delivering $g_{m}^{h}$ when effort is high. In addition, there is another unobservable set of actions, not explicitly modeled, that workers will only undertake if they buy into the mission of the organization. It is this set of actions that account for the higher level of mission good provision, $\widehat{g}_{m}$, that the organization can achieve with better matching. ${ }^{13}$

\subsection{Workers}

In order to focus on incentive issues I assume that workers are risk neutral and have a within period utility function, separable in income $(y)$ and effort $(e)$. The per-period utility, $U_{i j}^{W}\left(y, \theta_{i j}, e\right)$,

\footnotetext{
${ }^{12}$ In reality, the difference between $g_{m}^{h}$ and $\widehat{g}_{m}$ would most likely correspond to differences in the quality of the service being produced. The model is consistent with this view, if we interpret output as being weighted by quality.

${ }^{13}$ The logic is similar to that in Akerlof and Kranton (2005), who emphasize the notion of workers' identity and argue that when workers identify with the goals of the organizations they are employed they might be willing to put in high effort with little wage variation. Here I take the view that workers' sense of identity stems from the particular mission the organization is committed to.
} 
attained by worker of type $i$ when working for employer of type $j$ is:

$$
U_{i j}^{W}\left(y, \theta_{i j}, e\right)= \begin{cases}y-e & \text { if } i=u \text { and } j=u \\ y+\theta^{l}-e & \text { if } i \in\left\{m_{1}, m_{2}\right\}, j \in\left\{m_{1}, m_{2}\right\}, i \neq j \quad \text { where } \theta^{h}>\theta^{l}>0 \\ y+\theta^{h}-e & \text { if } i \in\left\{m_{1}, m_{2}\right\}, j \in\left\{m_{1}, m_{2}\right\}, i=j\end{cases}
$$

The parameter $\theta_{i j}$ represents the intrinsic payoff of a mission-motivated worker, which accrues to the worker independently of the legal status of the organization (for-profit or nonprofit). If employed by one of the organizations, a worker receives an endogenous wage $w$, while if not employed workers are able to find work elsewhere at an exogenously given reservation wage $\bar{w}$, which does not require high effort. To rule out trivial outcomes, I assume that $p_{s} g_{s}\left(e_{1}^{h}, e_{2}^{h}\right)-2 e^{h}>2 \bar{w}$, where $p_{s}$ is the market price for good $g_{s}$, so it is productively efficient for workers to be employed by a firm and to choose high effort.

\subsection{Managers}

Unmotivated managers, type $u$, care only about personal consumption of the numeraire good $y$. On

the other hand, mission-motivated managers have preferences given by $u_{j}^{M}\left(y, g_{m}\right)$, for $j \in\left\{m_{1}, m_{2}\right\}$. That is, I allow mission-motivated managers, as I did above with mission-motivated workers, to derive personal nonpecuniary benefits from being involved in the delivery of collective goods. As in the case of workers, intrinsic motivations are present whether the manager sets up a nonprofit or a for-profit organization. Furthermore, I assume that the manager's type and the organization's form are common knowledge and so is the worker's type - whether he is mission-motivated or not; however, if he is, his precise mission type $\left(m_{1}\right.$ or $\left.m_{2}\right)$ is revealed to him and becomes public information only after working for one period.

Before entering a sector, a manager can choose whether to establish the organization as for-profit or nonprofit. Thus, a brief description of the differences between the two organizational forms is in order. The objective of the manager (residual claimant) of a for-profit firm is primarily to maximize profits $(\pi)$ for the organization. This assumption is standard in neoclassical economic analysis and does not warrant further justification. On the other hand, when an organization is nonprofit, it is not obvious what the objective of its manager is. Nevertheless, a defining characteristic of nonprofits is that they are subject to a nondistribution constraint, which stipulates that the manager of a nonprofit is banned from appropriating any net earnings from the organization's 
operations. ${ }^{14}$ I follow Glaeser and Shleifer (2001) in assuming that the effect of this is that a fraction of the firm's profits can indirectly accrue to her in the form of perquisites such as fewer work hours, better working conditions etc. ${ }^{15}$ This way of modeling the objectives of nonprofit managers makes operational the notion that these organizations can be instituted to have weaker incentives to pursue profits. Though it is true that for-profit firms may also be motivated to serve other goals, I maintain that they must be consistent with their primary responsibility which is to generate sufficient rewards to shareholders. Thus, I take the view that, as a first approximation, for-profit managers will face more high-powered incentives to maximize total firm value than their nonprofit counterparts. In keeping with this discussion, I assume that the decision making process within nonprofit organizations - represented by the actions of the manager (founder) in my analysis - balances the goals of maximizing profits and furthering the mission of the organization. I posit that the outcome of this can be represented by an induced per-period quasi-linear utility function for a manager of type $j$ who chooses organizational form $k$, where $k=f p$ denotes a for-profit organization and $k=n p$ indicates a nonprofit organization, given by:

$$
v_{j}^{k}\left(\pi, g_{s}\right)=\phi_{j}^{k} \pi+\gamma_{j s} b\left(g_{s}\right)
$$

where $\pi$ stands for profits and $b($.$) is a strictly increasing and concave function. The binary vari-$ able $\gamma_{j s} \in\{0,1\}$ captures managers' "care intensity", which is only present for mission-motivated managers when producing a mission-oriented good. The parameter $\phi_{j}^{k} \in[0,1]$ reflects the extent to which the organization's profits can be enjoyed as income by the manager - so the nondistribution constraint implies that $\phi_{j}^{f p}>\phi_{j}^{n p} \cdot{ }^{16}$

Note that when production is of the good without the mission component $g_{n}$, then $\gamma_{j n}=0$, so setting up a nonprofit firm in the non-mission sector only corresponds with reducing the utility a manager obtains from profit. Equation (2) captures, in a reduced-form, the fundamental trade-off that the manager faces in making the incorporating decision, highlighted by Glaeser and Shleifer (2001): commitment to nonprofit status signals greater care for the 'quality' of the public good, which, however, comes at the cost of restricted access to pecuniary rewards.

\footnotetext{
${ }^{14}$ It is important to note that such a constraint does not preclude the possibility that a nonprofit organization may be actually earning positive profits.

${ }^{15}$ In addition to the nondistribution constraint, nonprofit organizations do not have access to the equity capital market and may be also subject to regulations requiring that they engage in specific charitable, religious, educational or scientific activities in order to receive preferential tax treatment. We abstract from these issues here.

${ }^{16}$ For simplicity, I make no distinction between the owner and the manager of the firm, so that agency problems between ownership and control are assumed away.
} 


\section{The Employment Relational Contracts}

An important feature of the environment is that though the individual performance of the worker can be potentially assessed by the manager or supervisor, it is unverifiable by third parties, and as a result, no standard contractual instruments can be used to induce workers' effort. ${ }^{17}$ I abstract from the underlying details regarding the incentive provision problem and simply assume that workers' input and the intrinsic reward they receive, though potentially observable by the firm and the agent, are noncontractible. When an employer and a worker are engaged in a repeated, ongoing relationship, they may be able to sustain informal long-term relational contracts as a means to overcome the noncontractibility of worker's performance. In what follows I characterize the nature of the internship and volunteering relational contract between an exogenously given single manager-worker pair.

The two alternative relational contracts that are considered here are (a) The internship contract, which entails the vertical promotion of interns within an organization. Under this incentive structure, workers and managers are randomly matched. (b) The volunteering contract, which involves the horizontal sorting of workers to managers with similar mission preferences, after the unpaid stage. In the mission sector, this incentive structure will be shown to generate assortative matching of manager-worker pairs. Both sorts of self-enforcing contracts give rise to actions that could not be supported in a one-shot interaction, but which can be sustained when agents have a sufficiently high valuation of the future.

To generate exogenous job separations I assume that workers remain alive for another period with probability $\beta \in(0,1)$, while with the complementary probability, $(1-\beta)$, they die and are replaced by identical workers. ${ }^{18}$

In the present model, a worker faces the following career choices: what sector to seek employment ( $m$ or $n$ ), what type of employer $\left(u, m_{1}, m_{2}\right)$ to be matched with and how much effort to exert $\left(e^{h}\right.$ or $e^{l}$ ). To fix ideas, I describe briefly the successive stages in the career path of a typical worker who will enter into an implicit contract with a manager in a certain sector, assuming that such contracts exist in equilibrium, abstracting momentarily from issues of sector selection and matching

\footnotetext{
${ }^{17}$ For example, an aid worker's job description typically involves a variety of complex tasks: from direct care provision to drafting reports, fund-raising and lobbying. Performance related compensation in this context is rare because (a) The monitoring and measurement of a worker's contribution to these tasks is very costly (and certainly difficult to verify by a third party, such as the courts) or (b) it may be difficult to ascertain an individual worker's contribution (due to the team character of production) or (c) it may induce effort distortions (due to multi-tasking considerations).

${ }^{18}$ For convenience, I subsume the discounting factor of agents in $\beta$.
} 
which are considered subsequently. The given worker moves sequentially through three states: the general pool of workers, unpaid employment and paid employment (i.e. deferred wage position). In particular, the worker is born into the general pool where he receives an exogenous compensation $\bar{w}$ every period. At the end of each period there is an endogenous probability $\rho$ that the worker will exit the general pool and will find an unpaid employment position. Suppose that this occurs in period $t-1$; then the worker works for no pay during period $t$ and at the end of the period he transitions to a wage position with probability $(1-\beta)$, which is the probability that the currently paid worker dies; otherwise, he remains an unpaid worker for another period. ${ }^{19}$ If the worker is hired into a paid position he continues to work there until he dies.

I model the self-enforcing contracts as equilibrium strategies of a dynamic game between managers and workers. The first step of the analysis is to specify precisely the incomplete contract environment in which the repeated game is conducted.

\subsection{Information Structure and Within Period Timing}

The information structure of the repeated game between workers and organizations, at any time $t$, can be summarized as follows: ${ }^{20}$

Public Information. The identity of all previous employment pairs and the wage payment histories are common knowledge. In particular, all workers and managers know whether a separation has occurred but do not know whether the worker quit or was fired. A separation that has taken place because of a death of one of the parties is distinguishable from separations due to the other causes involving one of the parties violating a promise. Also, if a separation occurs because a volunteer transfers to a paid position with a different employer this is also distinguishable from a separation due to malfeasance. ${ }^{21}$ Note that a manager's public history includes the event of mistreatment of volunteers. By this I refer to the event where an organization which has been hiring volunteers into unpaid positions refuses to reciprocate by promoting workers from the volunteering pool into its own paid work vacancies. I assume that such practice becomes public information. ${ }^{22}$

\footnotetext{
${ }^{19}$ At this point the employer must decide whether to honour the promise to promote the worker or cheat by hiring another intern to fill the vacancy. I examine the conditions that ensure employers' incentive compatible behavior in the next section.

${ }^{20}$ For a similar treatment of the information structure in a dynamic game between workers and firms, see MacLeod and Malcomson (1989).

${ }^{21}$ For example, a letter of confirmation/recommendation from the employer outlining a volunteer's experience may be provided at the end of the assignment.

${ }^{22}$ When an organization cheats on the promise to promote a volunteer into its paid position, it hires instead an unpaid intern directly from the general pool and therefore ceases to employ a paid worker. I assume that this
} 
Worker's Private Information. A worker knows his own performance and whether the organization where he was employed in previous periods honoured any promises made to him.

Manager's Private Information. A manager knows the history of effort contributions of all her workers up to time $t$ (imperfectly) and whether she has delivered on promises made to her workers.

The sequencing of decisions within a period in the contracting game between a matched manager and worker is:

- The manager makes the hiring decision (if there is a vacancy).

- The manager decides whether to make a payment or not.

- The worker makes the effort decision.

- The manager observes imperfectly worker's effort contribution.

- The worker observes manager's hiring decision.

- Both parties decide whether to continue the employment relationship or not.

- The period ends and both players continue to the next period with probability $\beta$.

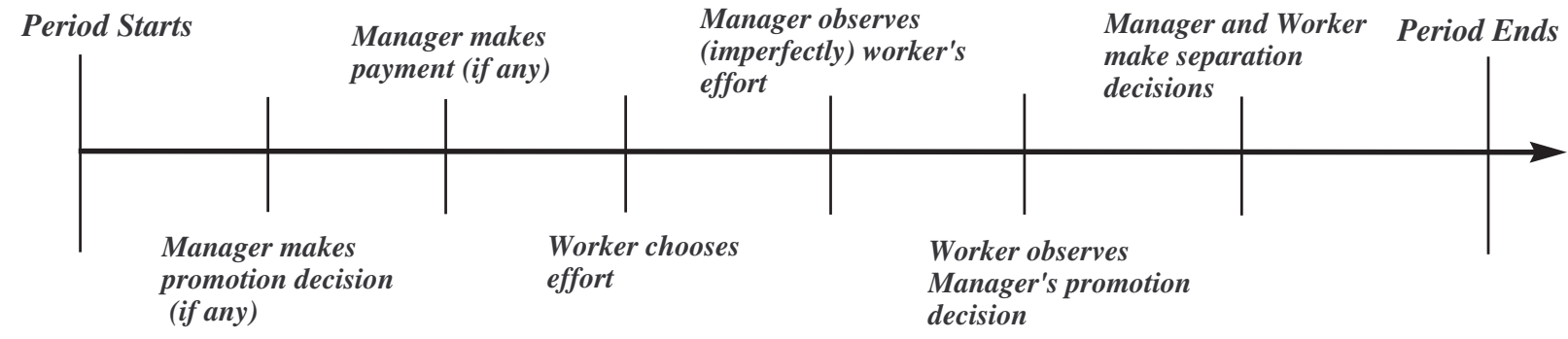

Figure 1: Timing of Events

\subsection{The 'Internship' Incentive Compatible Wage}

I now focus on the determination of the incentive compatible wage that induces an intern's effort. I consider a stationary environment, with employers offering the same wage $w^{I}$ every period and practice can be detected by labour market participants by observing the composition of the organization's workforce. Essentially what I assume is that whether the organization is employing paid workers or not is public information, which is verifiable information since wage payments are verifiable. 
the expected utility a worker gains from remaining in the general pool being constant. Letting $V_{i j t}^{I}$ represent the expected lifetime utility of a worker of type $i$ who accepts an unpaid position (internship) at an organization of type $j$ at time $t$, and suppressing the time subscripts I write:

$$
V_{i j}^{I}=-e^{h}+\beta\left[(1-\beta) V_{i j}^{p}+\beta V_{i j}^{I}\right]
$$

In this expression, $(1-\beta)$ denotes the probability that there will be a paid position vacancy and thus that the intern will be hired into a paid job. $V_{i j}^{p}$ designates the expected lifetime utility of a paid worker who decides to deliver high effort. An intern receives no compensation and provides high effort in the current period but expects to be hired into a paid job with probability $(1-\beta)$. Thus, $(1-\beta)$ acts as a quasi-discount factor on the value of becoming a paid worker.

Similarly, $V_{i j}^{p}$ is defined below:

$$
V_{i j}^{p}=w^{I}+\theta_{i j}-e^{h}+\beta \max \left(V_{i j}^{p}, V_{i j}^{s}\right)
$$

where $V_{i j}^{s}$ represents the expected utility of a worker who decides to shirk. If a worker supplies high effort then he attains utility $w^{I}+\theta_{i j}-e^{h}$ during the course of the current period, where $w^{I}$ is the wage associated with the position in an organization of type $j$ and $\theta_{i j}$ is the intrinsic reward for individual of type $i$ associated with a position in an organization of type $j$. If the job is continued, then the worker decides whether to furnish high effort next period or not, if doing so yields greater utility to him than shirking.

When a worker shirks, he receives the wage $w^{I}$ and the nonpecuniary benefit $\theta_{i j}$ but does not undergo the disutility of supplying effort. A shirking worker is detected with a constant exogenous probability $\mu \in(0,1)$, in which case he loses the job at the end of the period, and goes undetected with probability $(1-\mu)$ in which case he makes the effort decision again next period. ${ }^{23}$ I write the value function of a shirker as:

$$
V_{i j}^{s}=w^{I}+\theta_{i j}+\beta\left[\mu V^{g}+(1-\mu) \max \left(V_{i j}^{p}, V_{i j}^{s}\right)\right] .
$$

\footnotetext{
${ }^{23}$ The assumption of a less than perfect monitoring technology can be justified by the costs associated with supervision. In addition, I assume that inference of effort via observing output is impossible because of noise and the difficulties of identifying individual contributions due to the team character of production.
} 
Finally, the value function of being in the outside general pool is:

$$
V^{g}=\bar{w}+\beta\left[\rho V_{i j}^{I}+(1-\rho) V^{g}\right]
$$

where $\bar{w}$ is the general pool compensation and $\rho$ is the probability of moving out of the unemployment state.

Let us now consider the incentives that employers face in designing the relational contract. Their strategy is to minimize labor costs subject to being able to attract interns and induce them to provide high effort. Consequently, they will choose $w^{I}$ such that the prospective worker is no worse-off from becoming an intern and not remaining in the general pool, i.e. the following participation constraint must be satisfied:

$$
V_{i j}^{I} \geq V^{g}
$$

If $V_{i j}^{I}>V^{g}$, then it is in the firm's best interest to adjust the features of the package and transfer the surplus from the worker to itself such that internships are no more attractive than the outside option. The only means of adjusting the package, since the probability of transitioning from unpaid to paid work $(1-\beta)$ is exogenous, is to reduce the wage associated with a paid position. Let the wage solving (PC) with equality be $w^{P C}$. Substituting from (3), (6) and (4) it can be shown that:

$$
w^{P C}=\frac{1+\beta}{\beta}\left(e^{h}+\bar{w}\right)-\theta^{r}
$$

where $\theta^{r}$ is the expected intrinsic payoff when workers and firms are randomly matched. $\left(\theta^{l}<\theta^{r}<\right.$ $\left.\theta^{h}\right)$. Also, to deter shirking by the worker, the wage offered to the worker must satisfy the following incentive compatibility (no-shirking) constraint:

$$
V_{i j}^{p} \geq V_{i j}^{s}
$$

This condition implies:

Lemma 1 If the probability of detection of a shirking worker is sufficiently low, $\mu<\frac{(1-\beta) e^{h}}{\bar{w}+e^{h}}$, then the relational contract $\left(w^{I}, e^{h}\right)$ between an intern/worker and a firm consists of a wage satisfying:

$$
w^{I}(\rho)=\frac{\left(1-\beta^{2}\right)(1+\beta \rho-\beta(1-\mu))}{\beta \mu\left(1+\beta \rho-\beta^{2}\right)} e^{h}+\frac{\left(1-\beta^{2}\right)}{\left(1+\beta \rho-\beta^{2}\right)} \bar{w}-\theta^{r}
$$


with $\frac{\partial w^{I}(\rho)}{\partial \rho}>0$

Proof. Proof is in Appendix B.

Note that the assumption on the primitives $\left(\mu<\frac{(1-\beta) e^{h}}{\bar{w}+e^{h}}\right)$ is needed to ensure that the wage in $(I C I)$ is at least as high as the wage in (7), which is necessary to induce participation by workers in the general pool. The incentive compatible wage in $(I C I)$ admits a standard efficiency wage type of interpretation. That is, to induce effort the organization has to pay the worker a premium over his market alternative. Intuitively, the relational contract defined above allows the organization to elicit effort from the worker while limiting the rent offered to him. This is accomplished because while the worker gets a wage premium while occupying an efficiency wage position, the rent is partially taxed back by making the worker pay an "entrance fee" in the form of the uncompensated effort he has to supply as an intern. ${ }^{24}$ This arrangement encourages interns to stay with the firm and supply high effort throughout their career in order to benefit from the higher wages that come with seniority.

For the relational contract in $(I C I)$ to be supported in equilibrium, a sufficient rent has to be generated from employment. The rent is the difference between the returns to the current arrangement and those that the two parties could achieve in their outside options. In this model, the surplus is divided between employers and workers. To see this note that an intern prefers his current status than staying in the outside pool $\left(V_{i j}^{I} \geq V^{g}\right)$. For employers, profits from hiring interns are trivially greater than profits from hiring straight from the outside pool, which would be the alternative way of filling a vacancy, because an intern generates as much lifetime expected profits as an outside worker when in a paid position, but also makes an uncompensated contribution to the firm's profits as an intern.

Note that I have ruled out the possibility that workers can post a performance bond (in the form of a negative hiring wage) during the internship stage of employment. If this were possible, then firms could use this instrument to bind the participation constraint of workers $\left(V_{i j}^{I}=V^{g}\right)$, thereby extracting the entire surplus from the employment relationship and clearing the labor market. In reality, however, performance bonds are rarely observed. One possible explanation for this absence is credit market imperfections that make it impossible for workers to raise the money for the bond. More generally, the possibility of posting performance bonds raises a host of issues, as it induces

\footnotetext{
${ }^{24}$ Essentially, our version of the shirking model allows an entrance fee to emerge which reduces the rent that the employer needs to concede in order to motivate the worker. The suppression of this mechanism in the original Shapiro and Stiglitz (1984) formulation-by assuming that the principal pays the same wage at every period-was considered a theoretical weakness of the efficiency wage theory (see Carmichael 1989).
} 
employers to cheat workers in various ways, so I proceed by assuming that firms leave some rents to workers.

\subsection{The 'Volunteering' Incentive Compatible Wage}

The volunteering employment structure resembles the internship structure except that volunteering is an implicit contract offered jointly by all participating organizations and not by one specific employer. In particular, the volunteer is initially randomly matched with an organization and supplies high effort for that employer with no compensation; subsequently, the volunteer learns his type and when a paid position in an organization of the same type is vacated he transitions to that position even if this means transferring to a different organization. I examine managers' incentives to sustain this structure in the next subsection.

In addition to providing incentives, since volunteering is recognized by other firms, it plays the role of facilitating matching between mission-motivated workers and organizations. ${ }^{25} \mathrm{I}$ posit a frictionless matching process: the matching is instantaneous and costless. I look for allocations of workers to organizations that are voluntary and stable, in the sense that there is no pair that could negotiate an agreement that would make both parties better off than they are in their current matches. The following lemma characterizes the nature of stable matching in the mission sector.

Lemma 2 Any stable matching equilibrium must have organizations and workers assortatively matched.

Proof. Proof is in Appendix B.

I now turn to the determination of the incentive compatible wage for an organization hiring volunteers. The value functions of being in any of the three possible states, employed and paid, employed and unpaid (volunteer) and unemployed are identical to the ones in (3), (6), (4) and (5). Therefore, maintaining the notation I established in the previous section, incentive compatible wages that support assortative matching have to satisfy the following two conditions:

$$
V_{i j}^{p} \geq V_{i j}^{s}
$$

and

$$
w_{i i}^{V}+\theta^{h} \geq w_{i j}^{V}+\theta^{r}
$$

\footnotetext{
${ }^{25}$ In equilibrium, volunteering only occurs in the mission sector, this will be proved later, but for now we take it as given.
} 
The first condition is standard and ensures that the worker supplies high effort. The second condition ensures that the payoff to a worker when working for an organization of the same type is at least as high as when working for an organization of a different type.

Lemma 3 The relational contract $\left(w^{V}, e^{h}\right)$ between a volunteer/worker and a firm consists of a wage satisfying:

$$
w^{V}(\rho)=\frac{\left(1-\beta^{2}\right)(1+\beta \rho-\beta(1-\mu))}{\beta \mu\left(1+\beta \rho-\beta^{2}\right)} e^{h}+\frac{\left(1-\beta^{2}\right)}{\left(1+\beta \rho-\beta^{2}\right)} \bar{w}-\theta^{h}
$$

with $\frac{\partial w^{V}(\rho)}{\partial \rho}>0$.

Proof. Proof is in Appendix B.

The interpretation of the incentive compatibility wage for volunteering is analogous to that offered above for internship. The analysis of the two alternative self-enforcing mechanisms can be summarized in the following proposition:

Proposition 1 Conditional on a common job acquisition rate $(\rho)$, binding incentive compatible wages in the mission sector are higher under an 'Internship' relational contract than a 'Volunteering' relational contract $\left(w^{I}(\rho)>w^{V}(\rho)\right)$.

Proof. Follows directly from $(I C I),(I C V)$ and noting that $\theta^{h}>\theta^{r}$.

As in Besley and Ghatak (2005), selecting workers with congruent preferences can be cost saving for organizations, as this allows them to induce high effort at a lower wage. In addition, there are productivity gains to be made since volunteering ensures the better matching which raises workers' output. Consequently, those firms that can attract volunteers will be at an advantage. This feature is absent in the non-care sectors of the economy, so for employers a volunteering contract in those sectors is not preferred to the internship contract discussed above.

The workings of the matching process I envisage between mission-motivated principals and agents resemble that of the entry-level medical labor market. There it was recognized that mismatches occurred because competition led hospitals to sign up medical students early on, years ahead of graduation, before their skills and interests were developed. ${ }^{26}$ I believe that the process of volunteer hiring described above alleviates a similar problem - albeit in a less structured fashion

\footnotetext{
${ }^{26}$ The problem was that when a hospital and a student reached an early deal they did not take into account the externality imposed on other hospitals and interns (Roth 1984). Some rules were eventually designed to move the dates of appointment later into the senior year of medical school when more information about students' abilities and preferences was available and as a result more efficient matches between interns and hospitals were identified.
} 
than the labor market for medical residents - that would arise if mission-oriented organizations hired workers too soon (as would be the case with internships), before their mission preferences have been revealed.

It now remains to establish that the wages and employment patterns which have been computed for a single worker can constitute an equilibrium of the multi-player game.

\section{Selection of Relational Contract and Organizational Form}

\subsection{Non-mission Sector}

In the non-mission sector mission matching plays no role. It follows that in the non-mission sector managers will find it optimal to set up for-profit firms since the for-profit status makes them full residual claimants of the organization's net earnings. This feature of the model is also consistent with the observation that nonprofit firms are absent from sectors of the economy which do not involve mission-oriented production.

Furthermore, since there is no issue of matching managers and workers in this sector internships is the preferable hiring policy. However, when an internship structure is implemented there is still scope for opportunistic behavior on the part of managers. In particular, when a paid position vacancy is created in an organization which has been hiring interns then its manager has an incentive not to honour the promise to hire the existing intern into the paid position, but to fill the position with an unpaid worker from the general pool. Such behavior once detected by labor market

participants results in loss of reputation and is punished in future labor market interactions by the workers' equilibrium strategies. That is, in future periods workers will not be willing to be recruited as unpaid interns and the manager would have to resort to paying both of its workers an up-front wage $w^{I}$ satisfying $(I C I)$. Equilibrium strategies supporting the internship hiring structure are defined in Appendix A.

The incentive compatibility condition of the manager may be written as follows:

$$
\frac{1}{1-\delta} v^{f p}\left(\pi^{I}\right) \geq v^{f p}\left(\pi^{I d}\right)+\frac{\delta}{1-\delta} v^{f p}\left(\pi^{e}\right)
$$

or equivalently

$$
\frac{1}{1-\delta} \pi^{I} \geq \pi^{I d}+\frac{\delta}{1-\delta} \pi^{e}
$$

where $\pi^{I}, \pi^{I d}$ and $\pi^{e}$ denote per-period profits under an internship structure, the deviation, and 
in the periods after the deviation respectively, and $\pi^{I d}>\pi^{I}>\pi^{e}$. For future reference, it is useful to rewrite (11) as:

$$
\pi^{I} \geq(1-\delta) \pi^{I d}+\delta \pi^{e} \equiv K
$$

This incentive constraint must be satisfied for the internship structure to be a credible recruitment strategy. With free entry into the non-mission sector, the level of profits that a manager can enjoy in equilibrium will satisfy (12) as equality. Notice that adding heterogeneity among unmotivated agents would not lead to the implication that there is a nonprofit advantage in the non-mission sector as well because of the absence of the non-pecuniary component in managers' payoff.

\subsection{Mission Sector}

The purpose of this sub-section is to explore the role of the interaction between the choice of organizational form and the presence of mission preferences for the type of implicit contract that managers will use, in equilibrium, to overcome the non-contractibility problem of workers' effort. In what follows, I analyze whether it is incentive compatible for managers to implement volunteer hiring. In particular, I shall show that under the stated assumptions on the preferences of the managers who control the organizations, a deviation from a volunteer structure is more valuable for for-profit firms, which in equilibrium is going to lead to volunteering being only available to nonprofit organizations.

For an organization that implements a volunteer hiring structure the composition of its workforce, at any time $t$, is one wage worker plus one volunteer who awaits promotion to a paid position next period and is going to be replaced by a new volunteer. Profits equal $\pi^{V}=p_{m} \widehat{g}_{m}-w^{V}$, where $p_{m}$ is the price of the final product which the firm takes as given. Similarly, for an organization which uses an internship structure, its workforce consists of one wage worker plus one intern who will be promoted if a wage position is vacated next period and will be replaced by a new intern. Profits equal $\pi^{I}=p_{m} g_{m}^{h}-w^{I}$, where $\widehat{g}_{m}>g_{m}^{h}$, reflecting the fact that interns are randomly matched with organizations.

Note that the volunteer relational contract described above creates a commitment problem on the part of the employer. Organizations have an incentive not to promote current volunteers to wage positions and to replace them with new volunteers from the general pool, thus appropriating the unpaid labor contribution made by volunteers. Workers anticipating that they will not receive the high future payments have no incentive to work and thus incentives are destroyed. Thus, for 
volunteer hiring to be sustainable it has to satisfy the manager's incentive compatibility condition.

Consider what constitutes a deviation from the volunteering structure. Suppose that a paid position vacancy is created. The organization deviates by reneging on the promise to hire an individual from the volunteering pool to fill its vacancy and instead hires an unpaid intern straight from the general pool to fill this position. By doing this, the manager makes a one-period gain from not having to pay the wage she would otherwise have to, if she continued to hire volunteers to paid positions, but has to resort to an internship structure to get around workers' moral hazard in future periods since workers will refuse to volunteer for her anymore. That is, organizations that cheat lose their reputations and are punished in future labor market dealings by the workers' equilibrium strategies. Punishment here consists of future workers refusing to volunteer for organizations who have previously chosen not to promote volunteers into paid positions and to instead only accept internship contracts from such organizations. ${ }^{27}$ This kind of grim trigger strategy requires that labor market participants can observe whether an organization is employing a paid worker or not. In particular, when a manager breaches the implicit agreement to promote a volunteer into a paid position and hires another unpaid worker then during the deviation she employs only unpaid workers; other potential workers can detect this - because wage payments are verifiable information - and so they rationally avoid volunteering for the organization in the future. Equilibrium strategies supporting the volunteer-hiring relational contract are explicitly defined in Appendix A.

Specifically, in the first period of deviation the manager hires two interns to fill both the vacant paid position and the unpaid position. Profits are $\pi^{V d}=p_{m} g_{m}^{h}$. The opportunistic manager then loses the goodwill of being an honest employer so in future periods workers only accept internship positions that are more costly for the firm because $w^{I}>w^{V}$ - that is, the wage paid to interns is greater than the wage paid to volunteers. Also the mismatch induced because interns are randomly matched with organizations will also have an impact on the ability of the organization to successfully fulfill its mission. That is, following a deviation, the organization's mission good production is compromised $\left(g_{m}^{h}\right)$.

Hence, volunteering is self-enforcing if the present value of honouring is greater than the present

\footnotetext{
${ }^{27}$ Given this strategy of workers, the best response for managers who have reneged in the past is to continue cheating on the promise to promote volunteers, so that workers' strategies are a best response.
} 
value of reneging. The manager's incentive compatibility condition writes as:

$$
\begin{gathered}
\frac{1}{1-\delta} v_{j}^{k}\left(\pi^{V}, \widehat{g}_{m}\right) \geq v_{j}^{k}\left(\pi^{V d}, g_{m}^{h}\right)+\frac{\delta}{1-\delta} v_{j}^{k}\left(\pi^{I}, g_{m}^{h}\right) \\
\text { for each } j \in\left\{m_{1}, m_{2}\right\}, \text { and } k \in\{f, n\}
\end{gathered}
$$

where $\pi^{V d}>\pi^{V}>\pi^{I}$ and the last inequality follows from the fact that $w^{I} \geq w^{V}$. The left-hand side of (13) is a manager's discounted payoff from not cheating. The first term on the right-hand side of (13) represents the utility the manager can attain if she cheats. Note that this would raise profits but hurt the quantity of the mission good. ${ }^{28}$ The second term captures the expected present value payoff from hiring interns, which is the hiring practice the manager implements along the punishment path. My goal now is to determine for which organizational form incentive compatibility is easier to satisfy. Substituting from (2) into (13) yields:

$$
\frac{1}{1-\delta}\left[\phi^{k} \pi^{V}+b\left(\widehat{g}_{m}\right)\right] \geq\left[\phi^{k} \pi^{V d}+b\left(g_{m}^{h}\right)\right]+\frac{\delta}{1-\delta}\left[\phi^{k} \pi^{I}+b\left(g_{m}^{h}\right)\right]
$$

which upon rearrangement and simplification implies that:

$$
\pi^{V} \geq(1-\delta) \pi^{V d}+\delta \pi^{I}-\frac{1}{\phi^{k}}\left[b\left(\widehat{g}_{m}\right)-b\left(g_{m}^{h}\right)\right]
$$

Define the right-hand side of $(I C M)$ as $\Theta\left(\phi^{k}\right)$. The following result holds:

Proposition 2 In the mission sector, equilibrium level profits required to satisfy incentive compatibility of managers under a for-profit status is higher than that under a nonprofit status.

Proof. Because $\Theta\left(\phi^{k}\right)$ is increasing in $\phi^{k}$, and $\phi^{f p}>\phi^{n p}$ it follows that $\Theta\left(\phi^{f p}\right)>\Theta\left(\phi^{n p}\right)$.

To gain some intuition for this result notice that the way in which the reputation mechanism informally enforces managers' incentive compatible behavior is by offering to the potential cheater a "premium": a stream of payoffs that exceed the potential gain from cheating. This premium is given in both monetary (i.e. higher profits) and intrinsic (i.e. more quantity) terms. Under nonprofit status profits are less valuable for a manager - because they can only be enjoyed as perks - so a nonprofit manager places relatively more weight on the fact that if she cheats on volunteers quantity will suffer, and hence a smaller monetary premium is needed to maintain incentive compatibility.

\footnotetext{
${ }^{28}$ Note that for cheating to be worthwhile it has to be that $\phi^{k}\left(\pi^{V d}-\pi^{V}\right) \geq b\left(\widehat{g}_{m}\right)-b\left(g_{m}^{h}\right)$. That is, the monetary benefit from cheating (due to higher profits) has to be greater than the intrinsic loss a manager suffers (due to quantity degradation). In what follows we assume that this is always true.
} 
This is further illuminated by inspecting $(I C M)$ : the term that is subtracted from the right-hand side captures how heavily the loss of quantity - due to cheating - is discounted. The role that mission heterogeneity plays in the model now becomes clear: if cheating did not affect quantity then this term would be zero so the right-hand side of the inequality would be the same across firm types, and no organizational form would find it easier to attract volunteers. But to the extent that volunteering does affect the quantity of the service provided, the term is positive, so nonprofit incorporation relaxes the incentive compatibility condition that makes commitment to hiring volunteers credible. This suggests that volunteer hiring by nonprofits should occur only in fields where matching on mission heterogeneity has a noticeable effect on quantity.

Proposition 2 has the following important implication.

Corollary 1 For-profit firms will not be able to participate in a volunteer hiring structure that is just incentive compatible for nonprofit firms.

Free entry in the mission sector will ensure that the incentive compatibility condition of the nonprofit firm $(I C M)$ binds. However, when this is the case, incentive compatibility for forprofit firms will be violated which means that they cannot credibly commit to hiring volunteers. Furthermore, if a mission-motivated manager were to enter the mission sector establishing a forprofit firm and implement an internship structure she would be outcompeted by existing not-forprofit firms recruiting volunteers because of their lower labor costs. Thus, incorporation as nonprofit is valuable for managers because it serves as a commitment device that signals potential volunteers that they will be fairly treated. The very factor that is usually thought of as accounting for the efficiency supremacy of for-profit governance - high-powered incentives - can rule out participation in the volunteering incentive structure in mission-oriented sectors.

The model's prediction that only nonprofit firms will participate in a volunteering structure and that this will occur in mission-related activities is consistent with even a casual observation of the pattern of sectoral distribution of volunteer activity, according to which nonprofit agencies are the overwhelming recipients of volunteering services. This is even true in mixed ownership industries (childcare, nursing homes etc) where for-profits coexist and compete against nonprofits in both the output and labor markets.

For a different perspective on the difficulties associated with sustaining the volunteer-hiring structure notice that, because incentives are sector-wide and not employer-specific, their provision has the character of a public good and is susceptible to a form of free-riding. That is, each individual 
employer would like to obtain labor donations from volunteers but refrain from reciprocating by subsequently hiring them into paid positions, thereby free-riding on other organizations' hiring of volunteers. When the free riding is severe - i.e. when condition (13) fails - it leads to the unraveling of the volunteering structure. The implication of Proposition 2 is that organizing the production of mission goods by nonprofit organizations is a less costly way to overcome this kind of free-riding problem.

\section{Conclusion}

This paper helps us understand a number of related observations regarding volunteer activity and the sectoral concentration of nonprofit firms. By committing not to distribute surpluses, the nonprofit status ensures that the social mission takes precedence over the financial remuneration of any interested parties. This paper shows that this commitment allows nonprofit firms alone to sustain a sector-wide incentive structure - volunteer hiring - which is capable of initially extracting labor donations from volunteers and subsequently compensates them with higher wages as they transition to paid positions.

In addition, I argued that volunteering facilitates the matching of workers and organizations with similar mission preferences. The tighter congruence of organizations' and workers' goals in nonprofit organizations offers them a competitive advantage in mission-oriented sectors. In the nonmission oriented sector of the economy there is no scope for nonprofit organizations to be founded since the for-profit structure is preferable in that it allows the manager/owner to fully appropriate profits, whereas the nonprofit status rules out this possibility. Consequently, the simple framework developed here explains endogenously the observed dichotomy that the mission-oriented sector is associated with nonprofit organizations, which hire volunteers and sort them into paid positions based on their intrinsic preferences, whereas the non-mission sector is occupied by profit taking firms which hire interns.

The model presented here takes a stylized approach to modeling volunteer hiring focusing on incentive provision (rent extraction) and matching, since my main objective has been to provide a rationale for the fact that nonprofit organizations can exclusively tap into the pool of volunteer workers. I have left out of the analysis the possibility that volunteering may also act as a signal of workers' type as well as an investment in human capital, which are interesting perspectives that can generate additional insights into the workings of the volunteer labor market. Incorporation of 
such considerations into the current framework is left for future work.

\section{References}

[1] Akerlof, G. and L. Katz (1989) 'Workers trust funds and the logic of wage profiles.' Quarterly Journal of Economics, 104(3), 525-536.

[2] Akerlof, G. and R. Kranton (2005) 'Identity and the economics of organizations.' Journal of Economic Perspectives, 19(1), 1167-1201.

[3] Andreoni, J. (1990) 'Impure altruism and donations to public goods: A theory of warm-glow giving.' Economic Journal, 100(401), 464-477.

[4] Besley, T. and M. Ghatak (2005) 'Competition and incentives with motivated agents.' American Economic Review, 95(3), 616-636.

[5] Carmichael, L.H. (1989) 'Self-enforcing contracts, shirking, and life cycle incentives.' Journal of Economic Perspectives, 3(4), 65-83.

[6] Day, K.M. and R.A. Devlin (1998) 'The payoff to work without pay: Volunteer work as an investment in human capital.' Canadian Journal of Economics, 31(5), 1179-1191.

[7] Delfgaauw, J. and R. Dur (2007) 'Signaling and screening of workers' motivation.' Journal of Economic Behavior and Organization, 62(4), 605-624.

[8] Delfgaauw, J., and R. Dur (2008) 'Incentives and Workers' Motivation in the Public Sector.' Economic Journal, 118(525), 171-191.

[9] Dixit, A. (2002) 'Incentives and organizations in the public sector: An interpretative review.' Journal of Human Resources, 37(4), 696-727.

[10] Dur, R. and J. Tichem (2013) 'Altruism and Relational Incentives in the Workplace.' Journal of Economics and Management Strategy, forthcoming.

[11] Francois, P. (2000) 'Public service motivation' as an argument for government provision.' Journal of Public Economics, 78(3), 275-299.

[12] Francois, P. (2003) 'Not-for-profit provision of public services.' Economic Journal, 113(486), C53-61. 
[13] Francois, P. (2007) 'Making a difference.' RAND Journal of Economics, 38(3), 714-732.

[14] Francois, P., and Vlassopoulos, M. (2008): "Pro-social Motivation and the Delivery of Social Services," CESifo Economic Studies, 54(1): 22-54.

[15] Freeman, R.B. (1997) 'Working for nothing: The supply of volunteer labor.' Journal of Labor Economics, 15(1), S140-S166.

[16] Ghatak, M. and H. Mueller (2011) 'Thanks for nothing? Not-for-profits and motivated agents.' Journal of Public Economics, 95, 94-105.

[17] Glaeser, E. and A. Shleifer (2001) 'Not-for-profit entrepreneurs.' Journal of Public Economics, 81(1), 99-115.

[18] Glazer, A. (2004) 'Motivating devoted workers.' International Journal of Industrial Organization, 22(3), 427-440.

[19] Gunderson, M. and R. Gomez (2003) 'Volunteer activity and the demands of work and family.' Industrial Relations, 58(4), 573-587.

[20] Hall, M., D. Lasby, S. Ayer and W.D. Gibbons (2009) Caring Canadians, Involved Canadians: Highlights from the 2007 Canada Survey of Giving, Volunteering and Participating, Statistics Canada, catalogue no. 71-542-XIE.

[21] Handy, F., R. Cnaan, L. Hustinx, C. Kang, J. L. Brudney, D. Haski-Leventhal, K. Holmes, L. C. P. M. Meijs, A. Birgitta Pessi, B. Ranade, N. Yamauchi, and S. Zrinscak (2010) 'A CrossCultural Examination of Student Volunteering: Is It All About Rsum Building?' Nonprofit and Voluntary Sector Quarterly, 39, 498-523.

[22] Handy, F. and E. Katz (1998) 'The wage differential between nonprofit institutions and corporations: Getting more by paying less?' Journal of Comparative Economics, 26(2), 246-261.

[23] Hansmann, H. (1980). 'The role of nonprofit enterprise.' Yale Law Journal, 89, 835-901.

[24] Johnson, W. R. (1978). 'A theory of job shopping.' Quarterly Journal of Economics, 92(2), $261-77$.

[25] Jovanovic, B. (1979). 'Job matching and the theory of turnover.' Journal of Political Economy, $87(5), 972-9$. 
[26] Lazear, E. (1981) 'Agency, earnings profiles, productivity and hours restrictions.' American Economic Review, 71(4), 606-620.

[27] Leete, L. (2001) 'Whither the nonprofit wage differential? Estimates from the 1990 Census.' Journal of Labor Economics, 19(1), 136-170.

[28] Levin, J. (2003) 'Relational incentive contracts.' American Economic Review, 93(3), 835-847.

[29] Low, N., S. Butt,, E. Paine, A. and D.J. Smith (2007) Helping Out: A national survey of volunteering and charitable giving. London: Cabinet Office.

[30] MacLeod, W.B. and J.M. Malcomson (1989) 'Implicit contracts, incentive compatibility, and involuntary unemployment.' Econometrica, 57(2), 447-80.

[31] MacLeod, W.B. and J.M. Malcomson (1998) 'Motivation and markets.' American Economic Review, 88(3), 388-411.

[32] Malcomson, J.M. (1999) 'Individual employment contracts.' in Handbook of Labor Economics, Vol. 3, O. Ashenfelter and D. Card (eds). North Holland.

[33] Menchic, P.L. and B. Weisbrod (1987) 'Volunteer labor supply.' Journal of Public Economics, $32(2), 159-183$.

[34] Murdock, K. (2002) 'Intrinsic motivation and optimal incentive contracts.' Rand Journal of Economics, 33(4), 650-671.

[35] Prendergast, C. (2007) 'The Motivation and Bias of Bureaucrats.' American Economic Review, 97(1): 180-196.

[36] Roeger, K., A. S. Blackwood, and S. L. Pettijohn (2012) The Nonprofit Almanac 2012, The Urban Institute.

[37] Roth, A. E. (1984) 'The evolution of the labor market for medical interns and residents: A case study in game-theory.' Journal of Political Economy, 92(6), 991-1016.

[38] Rowat, C. and P. Seabright (2006) 'Intermediation by aid agencies.' Journal of Development Economics, 79(2), 469-491. 
[39] Salamon, L.M., M.A. Haddock, S.W. Sokolowski, and H. Tice (2007) Measuring Civil Society and Volunteering: Initial Findings from Implementation of The UN Handbook on Nonprofit Institutions. The Johns Hopkins Center for Civil Society Studies, Working Paper No. 23.

[40] Sauer, R. (2012) 'Does it Pay for Women to Volunteer?' IZA Discussion Paper, No 6784.

[41] Segal, L. M. and B. Weisbrod (2002) 'Volunteer labor sorting across industries.' Journal of Policy Analysis and Management, 21(3), 427-447.

[42] Shapiro, C. and J. E. Stiglitz (1984) 'Equilibrium unemployment as a worker discipline device.' American Economic Review, 74(3), 433-444.

[43] Weitzman, M. C. and N. T. Jalandoni (2002) The New Nonprofit Almanac and Desk Reference, Independent Sector, New York: Jossey-Bass. 


\section{A Appendix A: Equilibrium Strategies Supporting the Relational Contracts.}

\section{A.1 Information Sets}

Let $h_{i}^{w}(t)$ denote worker $i^{\prime} s$ public history up to time $t$, with $h_{i}^{w}(t)=1$ if the worker has not been involved in a separation due to cheating, and $h_{i}^{w}(t)=0$, otherwise. Similarly, a manager $j^{\prime} s$ public history is denoted $h_{j}^{m}(t)$, with $h_{j}^{m}(t)=1$ if the manager has not been involved in a separation due to cheating, and $h_{j}^{m}(t)=0$, otherwise. Let $q_{i}(t)$ denote worker $i^{\prime} s$ effort contribution up to time $t$, with $q_{i}(t)=1$ if the worker has delivered promised effort and $q_{i}(t)=0$, otherwise. Also, let $f_{j}(t)$ denote whether manager $j$ has honoured all previous promises made to workers, with $f_{j}(t)=1$ if she has and $f_{j}(t)=0$ otherwise.

Furthermore, if worker $i$ has provided promised effort when working for $j$ or has shirked but has not been caught (an event which occurs with probability $1-\mu$ ) then let $q_{i j}(t)=1$, whereas if the worker has been caught shirking (an event which occurs with probability $\mu$ ) it is $q_{i j}(t)=0$. Similarly, let $f_{i j}(t)$ denote whether manager $j$ has honoured all previous promises made to worker $i$, with $f_{i j}(t)=1$ if all promises were honoured and $f_{i j}(t)=0$, otherwise.

Agents know all previous wage payments made since this is verifiable information. Let $H(t)=$ $\left\{w_{0}, w_{1}, \ldots w_{t-1}\right\}$ denote the history of wage payments made up to time $t$.

Let $\mathcal{W}$ denote the set of all workers and $\mathcal{M}$ the set of all managers, then worker $i^{\prime} s$ information set in period $t$, is given by the collection of the public histories of all workers and managers up to time $t-1, h^{\mathcal{W}}(t-1) \cup h^{\mathcal{M}}(t-1) \cup H(t-1)$, as well as the private information he has from his own employment history $q_{i}(t-1)$ and his interactions with employers $\underset{j \in \mathcal{M}_{i}}{\cup} f_{i j}(t-1)$, where $\mathcal{M}_{i}$ is the set of managers for whom worker $i$ has worked. Similarly, manager $j^{\prime} s$ information set in period $t$ comprises the collection of the public histories of all workers and managers up to time $t-1, h^{\mathcal{W}}(t-1) \cup h^{\mathcal{M}}(t-1) \cup H(t-1)$, as well as the private information she has from her own history as employer $f_{j}(t-1)$ and her interactions with her workers $\underset{i \in \mathcal{W}_{j}}{\cup} q_{i j}(t-1)$, where $\mathcal{W}_{j}$ is the set of workers that manager $j$ has employed.

\section{A.2 Strategy Space}

Strategies consist of rules that specify a worker's and a manager's set of actions at each information set and time $t$. 
- Worker: A strategy $\sigma^{w}(t)$ for the worker specifies two sorts of actions. First, it specifies whether to accept an employment offer (volunteering or internship) from every manager. An offer consists of an unpaid position along with a promise of promotion to a wage position (within the organization in the case of an internship, in an organization of matching type in the case of volunteering), when a vacancy is created, as well as a wage offer $(w)$. In the second stage, for a worker who has accepted the offer from a given employer, and is either in the unpaid or the paid position, the strategy specifies whether to provide high effort $\left(q_{i}=1\right)$ or not $\left(q_{i}=0\right)$ and whether to continue in the employment relationship or quit.

- Manager: A strategy $\sigma^{m}(t)$ for a manager specifies the following set of actions. Firstly, it specifies what type of employment offer to make to workers: volunteering or internship, and the accompanying wages. Secondly, if a volunteering structure is implemented, it specifies whether to honour the promise to promote a worker from the pool of volunteers when a paid position opening has occurred $\left(f_{j}=1\right)$ or to renege on the promise $\left(f_{j}=0\right)$ by filling the vacancy with an intern hired from the general pool. Finally, it specifies whether to continue an employment relationship or not.

\section{A.3 Equilibrium Strategies Supporting the Volunteering Structure}

In what follows I describe the actions that the equilibrium strategies $\left(\sigma_{i}^{* w}(t), \sigma_{j}^{* m}(t)\right)$ supporting the volunteering structure prescribe in every possible information set.

\section{Worker's strategy $\sigma_{i}^{* w}(t)$ :}

1. If manager $j^{\prime} s$ incentive compatibility constraint, as defined in (13), is satisfied, and $h_{j}^{m}(t-$ $1)=1$ and $h_{i}^{w}(t-1)=1$, and $q_{i}(t-1) f_{i j}(t-1)=1$, then accept a volunteering position promising promotion to a wage position of $w^{V}$, satisfying $(I C V)$, and set $q_{i j}=1$. Otherwise, do not accept a volunteering position. If the worker is already in a paid position then accept any wage offer. If $h_{j}^{m}(t-1)=1$ and $h_{i}^{w}(t-1)=1$, and $q_{i}(t-1) f_{i j}(t-1)=1$, and the up-front wage $w^{V}$ satisfies $(I C V)$, then set $q_{i j}=1$, otherwise set $q_{i j}=0$.

2. If $h_{i}^{w}(t-1)=1$, and $q_{i}(t-1) f_{i j}(t-1)=1$, then accept an internship position in organization $j$ promising a wage of $w^{I}$, satisfying $(I C I)$, and set $q_{i j}=1$. Otherwise, do not accept an internship position. If the worker is already in a paid position then accept any wage offer. If 
$h_{i}^{w}(t-1)=1$, and $q_{i}(t-1) f_{i j}(t-1)=1$, and the up-front wage offer $w^{I}$ satisfies $(I C I)$, then set $q_{i j}=1$, otherwise set $q_{i j}=0$.

3. Terminate a relationship with a manager if promised promotion or promised wage offer have not been met.

\section{Manager's strategy $\sigma_{j}^{* m}(t)$ :}

1. If the manager's incentive compatibility constraint (13) is satisfied, and $h_{j}^{m}(t-1)=1$ and $h_{i}^{w}(t-1)=1$, and $q_{i j}(t-1) f_{j}(t-1)=1$, then: a) Offer worker $i$ a volunteering position. b) Honour the promise to promote a worker $i$ from the volunteer pool into a paid position $\left(f_{j}=1\right)$ whether $i$ has volunteered for $j$ or not, when there is a paid work vacancy. c) If a worker $i$ is an existing paid worker with $h_{j}^{m}(t-1)=1$ and $h_{i}^{w}(t-1)=1$, and $q_{i}(t-1) f_{i j}(t-1)=1$, who has received previous payment of $w \geq w^{V}$, make him an up-front wage offer of $w^{V}$ satisfying $(I C V)$.

2. If the manager's incentive compatibility constraint (13) is satisfied, and $h_{j}^{m}(t-1)=0$ and $h_{i}^{w}(t-1)=1$, and $q_{i j}(t-1) f_{j}(t-1)=1$, then: a) Offer worker $i$ an internship position. b) Honour the promise to promote a worker $i$ who has interned for you into a paid position $\left(f_{j}=1\right)$, when there is a paid work vacancy. c) If a worker $i$ is an existing paid worker with an internship history with you and $h_{j}^{m}(t-1)=1$ and $h_{i}^{w}(t-1)=1$, and $q_{i j}(t-1) f_{j}(t-1)=1$, then make him an up-front wage offer of $w^{I}$.

3. If (13) is satisfied, and $h_{j}^{m}(t-1)=1, h_{i}^{w}(t-1)=1$ and $q_{i j}(t-1) f_{j}(t-1)=0$, then make no offer to worker $i$.

4. If (13) is satisfied, and $h_{j}^{m}(t-1)=1$ and $h_{i}^{w}(t-1)=0$, then make no offer to worker $i$.

5. If (13) is violated, and $h_{j}^{m}(t-1)=0, h_{i}^{w}(t-1)=1$ and $q_{i j}(t-1) f_{j}(t-1)=1$, then: a) Offer worker $i$ an internship position b) Honour the promise to promote worker $i$ into a paid position $\left(f_{j}=1\right)$, when there is a paid work vacancy. c) If worker $i$ is an existing paid worker with an internship history and $h_{i}^{w}(t-1)=1$, and $q_{i j}(t-1) f_{j}(t-1)=1$, then make worker $i$ a wage offer of $w^{I}$.

6. If (13) is violated, and either $h_{j}^{m}(t-1)=0$, or $h_{i}^{w}(t-1)=1$, or $q_{i j}(t-1) f_{j}(t-1)=1$ does not hold, then make no offer to worker $i$. 
The above strategies induce a perfect equilibrium of the repeated game, in which managers choose to set up a volunteering structure. Workers accept volunteering positions with a promise of promotion to a paid position paying $w^{V}$ and choose not to shirk, while managers honour their promises to promote only workers with volunteering experience and rehire workers who have provided the promised effort. Note that the above strategies describe behavior both on and off the equilibrium path, for instance, after one of the parties reneges on a promise. To see this, note that under the equilibrium strategy $\sigma_{i}^{* m}(t)$ a manager who has cheated on a promise to promote volunteers and has therefore lost reputation, will continue to exploit future volunteers, and this would be a best response to workers' equilibrium strategy $\sigma_{i}^{* w}(t)$ of not accepting volunteer positions in organizations with stained reputations. In turn, a worker's best response facing a manager who has lost reputation is to only accept internship positions paying $w^{I}>w^{V}$, which is what the equilibrium strategy $\sigma_{i}^{* w}(t)$ prescribes. Also, this is the best the manager can do since under $\sigma_{i}^{* w}(t)$ workers offered a lower up-front wage will shirk. Or suppose that a worker shirks. Then the equilibrium strategy of the manager states that the worker should not be hired again. This is optimal given that the worker's equilibrium strategy says that a shirking worker will shirk again even if the wage offer is $w^{V}$. Furthermore, this is the optimal thing for the worker to do, since the equilibrium strategy of the manager calls for a shirking worker not to be hired again.

\section{A.4 Equilibrium Strategies supporting the Internship Structure Worker's strategy $\tilde{\sigma}_{i}^{w}(t)$ :}

1. If manager $j^{\prime} s$ incentive compatibility constraint, as defined in (11) below, is satisfied, and $h_{j}^{m}(t-1)=1$ and $h_{i}^{w}(t-1)=1$, and $q_{i}(t-1) f_{i j}(t-1)=1$, then accept an internship position promising promotion to a wage position of $w^{I}$, satisfying $(I C I)$, and set $q_{i j}=1$. Otherwise, do not accept an internship position. If the worker is already in a paid position then accept any wage offer. If $h_{j}^{m}(t-1)=1$ and $h_{i}^{w}(t-1)=1$, and $q_{i}(t-1) f_{i j}(t-1)=1$, and the up-front wage $w^{I}$ satisfies $(I C I)$, then set $q_{i j}=1$, otherwise set $q_{i j}=0$.

2. Accept any non-negative up-front wage offer. If $h_{i}^{w}(t-1)=1$, and $q_{i}(t-1) f_{i j}(t-1)=1$, and the up-front wage offer satisfies $w^{I}$ satisfies $(I C I)$, then set $q_{i j}=1$, otherwise set $q_{i j}=0$.

3. Terminate a relationship with an organization if promised promotion or promised wage offer have not been met. 


\section{Manager's strategy $\widetilde{\sim}_{j}^{m}(t)$ :}

1. If the manager's incentive compatibility constraint (11) is satisfied, and $h_{j}^{m}(t-1)=1$ and $h_{i}^{w}(t-1)=1$, and $q_{i j}(t-1) f_{j}(t-1)=1$, then: a) Offer worker $i$ an internship position. b) Honour the promise to promote a worker $i$ who has interned for you into a paid position $\left(f_{j}=1\right)$, when there is a paid work vacancy. c) If a worker $i$ is an existing paid worker with an internship history with you and $h_{j}^{m}(t-1)=1$ and $h_{i}^{w}(t-1)=1$, and $q_{i j}(t-1) f_{j}(t-1)=1$, then make him an up-front wage offer of $w^{I}$.

2. If the manager's incentive compatibility constraint (11) is satisfied, and $h_{j}^{m}(t-1)=0$ and $h_{i}^{w}(t-1)=1$, and $q_{i j}(t-1) f_{j}(t-1)=1$, then offer an up-front wage offer $w^{I}$ satisfying $(I C I)$.

3. If (11) is satisfied, and $h_{j}^{m}(t-1)=1, h_{i}^{w}(t-1)=1$ and $q_{i j}(t-1) f_{j}(t-1)=0$, then make no offer to worker $i$.

4. If (11) is satisfied, and $h_{j}^{m}(t-1)=1$ and $h_{i}^{w}(t-1)=0$, then make no offer to worker $i$.

5. If (11) is violated, and $h_{j}^{m}(t-1)=0, h_{i}^{w}(t-1)=1$ and $q_{i j}(t-1) f_{j}(t-1)=1$, then make worker $i$ a wage offer of $w^{I}$.

6. If (11) is violated, and either $h_{j}^{m}(t-1)=0$, or $h_{i}^{w}(t-1)=1$, or $q_{i j}(t-1) f_{j}(t-1)=1$ does not hold, then make no offer to worker $i$.

The above strategies give rise to a perfect equilibrium of the repeated game, in which workers accept internship positions with a promise of promotion to a paid position paying $w^{I}$ and choose not to shirk, while managers honour their promises to promote interns into paid positions and rehire workers who have provided the promised effort. 


\section{B Appendix B: Proofs}

Proof of Lemma 1: It is

$$
\begin{aligned}
V_{i}^{g} & =\bar{w}+\beta\left[\rho V_{i j}^{I}+(1-\rho) V_{i}^{g}\right] \\
& \Rightarrow V_{i}^{g}=\frac{\bar{w}+\beta \rho V_{i j}^{I}}{1-\beta(1-\rho)}
\end{aligned}
$$

and

$$
\begin{gathered}
V_{i j}^{I}=-e^{h}+\beta\left[(1-\beta) V_{i j}^{p}+\beta V_{i j}^{I}\right] \\
\Rightarrow V_{i j}^{I}=\frac{-e^{h}+\beta(1-\beta) V_{i j}^{p}}{1-\beta^{2}}
\end{gathered}
$$

while

$$
\begin{aligned}
V_{i j}^{p} & =w^{I}+\theta_{i j}-e^{h}+\beta V_{i j}^{p} \\
& \Rightarrow V_{i j}^{p}=\frac{w^{I}+\theta_{i j}-e^{h}}{1-\beta}
\end{aligned}
$$

and

$$
\begin{aligned}
V_{i j}^{s} & =w^{I}+\theta_{i j}+\beta\left[\mu V^{g}+(1-\mu) V_{i j}^{s}\right] \\
& \Rightarrow V_{i j}^{s}=\frac{w^{I}+\theta_{i j}+\beta \mu V^{g}}{1-\beta(1-\mu)}
\end{aligned}
$$

So, incentive compatibility implies:

$$
\begin{aligned}
& V_{i j}^{p} \geq V_{i j}^{s}=\frac{w^{I}+\theta_{i j}+\beta \mu V^{g}}{1-\beta(1-\mu)}=\frac{w^{I}+\theta_{i j}}{1-\beta(1-\mu)}+\frac{\beta \mu}{1-\beta(1-\mu)}\left(\frac{\bar{w}+\beta \rho V_{i j}^{I}}{1-\beta(1-\rho)}\right) \Rightarrow \\
& V_{i j}^{p} \geq \frac{w^{I}+\theta_{i j}}{1-\beta(1-\mu)}+\frac{\beta \mu \bar{w}}{(1-\beta(1-\mu))(1-\beta(1-\rho))}+\frac{\beta^{2} \mu \rho}{(1-\beta(1-\mu))(1-\beta(1-\rho))}\left(\frac{-e^{h}+\beta(1-\beta) V_{i j}^{p}}{1-\beta^{2}}\right)
\end{aligned}
$$

Substituting from (B-3) and rearranging yields the incentive compatible wage in (ICI).

Also note that straightforward computation yields: $\frac{\partial w^{I}(\rho)}{\partial \rho}=(1-\beta) e^{h}-\mu\left(\bar{w}+e^{h}\right)$, which is positive under the condition stated in the lemma. 
Proof of Lemma 2: An assortatively matched pair generates strictly more surplus than one where types differ. When workers' type matches the type of the organization, provision of the mission good $\left(g_{m}\right)$ is enhanced $\left(g_{m}=\widehat{g}_{m}>g_{m}^{h}\right)$. Consider a matching-equilibrium without assortatively matched pairs. An organization employing a worker of a different type would have an incentive to attract a worker of the same type by offering him some share of the higher surplus. This would also be preferred by the worker thus undoing the stability of the equilibrium.

Proof of Lemma 3: Similar to that of Lemma 1, so omitted. 